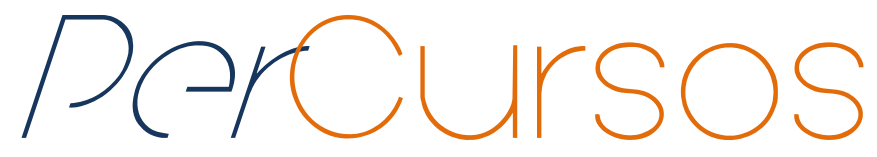

\title{
Cidades e migrantes contemporâneos: experiências de inclusão e segregação urbana em Lisboa e Sevilha. Uma conversa com o Prof. Francisco Cuberos
}

Entrevistadores

Francisco J. Cuberos é Ph.D. em Antropologia Social pela Universidade de Sevilha e tem licenciaturas em Antropologia Social e em Jornalismo nesta Universidade. Atualmente, é pesquisador pósdoc no Centro de Investigação e Estudos de Sociologia - Instituto Universitário de Lisboa (CIES-IUL). Ele está envolvido em vários projetos de investigação, incluindo GOVDIV, um projeto sobre governança multinível da diversidade cultural financiado pelo programa IRSES Marie Curie - $7^{\circ}$ Programa Marco. Seus principais interesses de pesquisa estão ligados às migrações e especialmente focados em associações de imigrantes, interculturalidade, integração social e relações interétnicas. Durante os últimos anos tem publicado vários trabalhos em inglês e espanhol, incluindo artigos em revistas científicas internacionais, livros e capítulos. Francisco Cuberos esteve conosco na UDESC, numa estadia do projeto GOVDIV - "Minorities, multiculturalism, interculture: institutional framework and policies. A comparison between Europe and Latin America" - em março deste ano, durante a qual, entre outras atividades desenvolvidas junto ao Observatório das Migrações da FAED, conversamos sobre a questão das cidades e as migrações contemporâneas e seus desafios.

Entrevista concedida em: 08/06/2015

\section{Gláucia de Oliveira Assis}

Doutora em Ciências Sociais pela Universidade Estadual de Campinas - UNICAMP/SP;

Professora da Univ. do Estado de Santa Catarina - UDESC. Brasil galssis@gmail.com

\section{Francisco Canella}

Doutor em Ciências Sociais pela Universidade do Estado do Rio de Janeiro - UFRJ; Professor da Universidade do Estado de Santa Catarina - UDESC. Brasil

franciscocanella@hotmail.com

\section{Transcrição}

Samira Moratti Frazão

Doutoranda em História na

Universidade do Estado de Santa

Catarina - UDESC.

Brasil

samiramoratti@gmail.com

\section{Para citar esta entrevista:}

CUBEROS, Francisco. Cidades e migrantes contemporâneos: experiências de inclusão e segregação urbana em Lisboa e Sevilha. Uma conversa com o Prof. Francisco Cuberos. [Entrevista realizada em 08 de junho de 2015]. Revista PerCursos. Florianópolis, v. 16, n.30, p. 243 - 259. jan./abr. 2015. Entrevistadores: Gláucia de Oliveira Assis e Francisco Canella. Transcrição: Samira Moratti Frazão. 
PerCursos: Gostaríamos de começar esta entrevista com você falando um pouco sobre a sua formação, seus temas de pesquisa, como você chegou a eles e quais seus interesses.

Francisco Cuberos: Eu estudei Antropologia em Sevilha e fiz lá o Doutoramento, sempre o mesmo tema, desde a Licenciatura, investigando temas relacionados com a imigração. A princípio, sobretudo, com imigração latino-americana em Sevilha, imigração de coletivos, que naquele momento estavam a chegar em grande número lá. E, comecei estudando, sobretudo, redes migratórias e estratégias de inserção e depois virei mais para a questão do associativismo entre migrantes. Quando finalizei a tese, achei que podia ser interessante uma comparação com outro contexto que eu tinha conhecido, que era Lisboa, onde os imigrantes estavam a criar também associações. Mas descobri que eram associações que tinham algumas importantes diferenças. A minha hipótese era que estavam ligadas, de um lado, àquilo que se chama estrutura de oportunidade política, que existiam numa e noutra cidade; de um outro lado, às culturas políticas de diferentes coletivos que chegavam a cada cidade, mas também a um modelo de inserção urbana. Eu achava, especialmente no caso dos africanos em Lisboa, que eles tinham feito um modelo de inserção urbana que condicionava muito a forma de sociabilidade deles e, portanto, também um associativismo. Foi assim que comecei a me interessar por esta questão da inserção urbana dos imigrantes. Ao longo desse processo, fiz doutoramento em Sevilha, na Antropologia, e o que estou a fazer agora é uma investigação de Pós-doc em Lisboa, um estudo comparativo.

PerCursos: Em sua pesquisa com imigrantes latinos em Sevilha, como é que se dava o processo de inserção nos espaços da cidade, como ocorre a construção de identidade nesses grupos? De que forma eles estão inseridos nesse contexto marcado por uma precariedade jurídica, econômica e habitacional?

Francisco Cuberos: Como estamos a falar de uma imigração bastante recente, e que também é uma imigração que tem se produzido numa condição de precariedade, pois a situação deles era muito difícil, mesmo para se encontrar, e para poder levar a cabo atividades que permitissem uma reprodução cultural e também uma integração social na 
sociedade receptora. Estas pessoas chegam geralmente numa situação de precariedade jurídica, porque às vezes não tem permisso para ficar lá, entravam como turistas, mas estavam numa situação irregular, não só uma situação de precariedade jurídica, mas também de precariedade residencial; eles chegam num momento em que o preço da moradia está muito alto, eles têm de se inserir numas condições muito difíceis a um nível residencial, partilhar casa entre muitas pessoas...

\section{PerCursos: E eles se concentram numa área da cidade?}

Francisco Cuberos: Não. Então, é o alto preço do valor de solo que dificulta a sua entrada. Eles alugam lá onde é mais barato. Mas é muito difícil encontrar grandes concentrações de população imigrante. Cada um chega lá onde pode e isso na prática, unido à própria precariedade laboral, com jornadas de trabalho muito longas, com baixos salários, portanto, também um nível de consumo muito baixo, isso vai fazer com que seja muito difícil para estas pessoas ter o tempo, os espaços e os recursos necessários para se juntar e ter uma forma de sociabilidade como a que elas tinham na sociedade de origem. Essa é uma grande diferença com o caso de Lisboa. Lá, os imigrantes tinham chegado a bairros onde eles concentravam-se e eram maioria e, apesar de todos os problemas que tinham, tinham os próprios espaços para se juntar. No caso de Sevilha, o que eu encontrei foi que, ante uma ausência de espaço, eles faziam formas de ocupação intensiva de espaços na periferia. Por exemplo, criavam discotecas, que eram lá onde nunca vão sevilhanos, na periferia, nos polígonos industriais e tudo, eles iam lá se juntar nas noites do fim de semana. Também usavam de uma forma intensiva canchas deportivas, que estavam ubicadas (localizadas) em parques e lugares na periferia, sempre infrautilizados porque isso era o que permitia a eles estar juntos, sem outras pessoas. Ao redor dessas ocupações espaciais na periferia, encontrei formas de associativismo muito importantes, ainda que normalmente informais. Então isso foi muito interessante pra minha tese, porque demonstrava que, para além das associações formais havia todo um campo de sociabilidade e de associativismo informal que, ainda que não tivesse legalmente reconhecido, era muito importante nas estratégias associativas destas pessoas, e nas suas estratégias de inserção urbana mesmo. 
PerCursos: Interessante... E com relação aos imigrantes cabo-verdianos em Lisboa, o que Ihe chamou mais atenção nessa relação deles com essa sociedade portuguesa?

Francisco Cuberos: Para mim, principalmente, acho que houve três coisas que foram muito importantes quando cheguei a Lisboa. De um lado, a própria atualidade da questão colonial. É interessante como a Espanha, que está ao lado, tem esquecido quase totalmente a sua história colonial. Se você fala com um espanhol da história colonial, no melhor dos casos vai pensar em latinoamerica. Mas a Espanha tem tido colônias até há muito pouco tempo. Por exemplo, a Guiné Equatorial ou o Saara. Mas isso foi borrado (apagado) da memória, foi esquecido muito rápido. No caso de Lisboa, foi totalmente diferente, não? Porque eles tiveram as guerras coloniais muito fortes; foi uma coisa traumática. Houve também um refúgio muito forte de portugueses que retornavam. Então quando você chega a Lisboa, e para um espanhol é impactante, porque apesar da cercania, tem sido um país que tem vivido de espaldas (às costas), como observamos, não tem tido muita relação, quando você chega o que encontra lá é que a história da colônia ainda tá muito viva. Há muita gente que, depois de você conhecer, muito tempo depois, você descobre que nasceu em Angola. Que tem família lá. Ou que tem lutado na guerra da Angola. É muito comum, porque é uma coisa recente. Mesmo na própria televisão. Há uma presença ainda, há uma RTP África, rede de televisão portuguesa na África mesmo. Nas pinturas, na rua, há uma presença muito forte da questão colonial. De um outro lado, e fortemente relacionado com isso, está muito presente em Portugal, ou de uma forma muito explícita, a questão racial. Racial num sentido fenotípico. Esse é um debate que na Espanha tem sido diferente, tem sido diferente. No caso português é muito importante a questão da cor da pele, mesmo discurso do cabo-verdiano nas suas estratégias associativas, também é mais presente. E finalmente pra mim foi muito, muito surpreendente, no caso dos cabo-verdianos, a questão da concentração espacial. Eles chegaram muito majoritariamente aos bairros da periferia de Lisboa. Lá, a concentração é muito forte e lá encontra aquilo que não vai encontrar em Sevilha, que são bairros onde os imigrantes são maioria. Você pode chegar lá em um bairro e $80 \%$ da população é imigrante, é africana. Isso é um padrão de distribuição espacial totalmente diferente de 
Sevilha. Em Sevilha, o bairro que pode ter mais população imigrante pode ter uma porcentagem talvez de, não sei, de $25 \%$ no máximo $20 \%$, talvez.

PerCursos: O que você acha que possibilita essa concentração espacial?

Francisco Cuberos: Essa concentração tem tido consequências em muitos níveis. De um lado para o próprio coletivo... sempre falamos de consequências tanto positivas quanto negativas, não? É difícil para o próprio coletivo, eu acho que tem permitido o desenvolvimento de estratégias de auto-organização e de solidariedade intragrupo muito importantes. Isso é uma questão interessante. Está muito presente, por exemplo, no discurso dos brasileiros em Portugal. Eles têm uma "inveja" dos caboverdianos, porque ainda que os cabo-verdianos tenham um perfil socioeconômico mais baixo e geralmente morem em condições mais difíceis, mas se tem logrado (conseguido) em desenvolver muito fortes, em muitas associações, tem muita presença nos bairros, nas juntas de freguesia, toda essa coisa. Então, isso é a parte boa. Eles têm conseguido que as redes migratórias, mesmo pelo momento em que foram feitas e as condições que encontraram, essas redes migratórias tiveram uma plasmação territorial e, portanto, uma continuidade. Uma forma de ajuda e solidariedade e tudo. A parte ruim é que isso, e tal como tem acontecido também no modelo de inserção urbana dos Estados Unidos, dá lugar ao debate sobre o gueto. As minorias étnicas concentradas num mesmo espaço têm como consequência uma estigmatização mesmo do espaço físico, do bairro, que dificulta, às vezes, a interação com a sociedade de fora. Nesse sentido, é muito interessante, por exemplo, algum trabalho que eu tenho feito sobre os discursos da compatibilidade cultural entre os latinoamericanos na Espanha e, não tão forte, mas também existe entre brasileiros em Portugal. Como é um discurso, eles dizem que o brasileiro se insere melhor do que o africano porque se espalha mais, se mistura, é mais próximo ao português, não é um contraste tão forte. Nesse contexto, que obviamente é só uma construção, que é muito discutível, mas nesse contexto, há fatores que se misturam muito interessantes: de um lado, óbvio, a questão da raça. 
PerCursos: Eu acho que classe e raça, não?

Francisco Cuberos: É, eu acho... classe, raça, muita coisa. Mas também essa questão espacial, de nós nos inserirmos melhor porque estamos espalhados. Para se ter ideia, que eu acho que é muito em dívida com os pressupostos da Escola de Chicago de que a boa integração é quando não se nota, não é? Quando o imigrante perde a identidade e não há um contraste. Há essa confusão entre a assimilação cultural e a integração social. Os africanos, como chegaram, fizeram os seus bairros e esses bairros ainda são muito visíveis, mesmo porque você cruza a rua, chega ao bairro cabo-verdiano e é gente negra, não? Que é muito evidente...

\section{PerCursos: É muito visível, não?}

Francisco Cuberos: Isso. É. E isso é visto às vezes como uma forma de falta de integração. Eu acho que não tem porque ser assim, mas vem porque o discurso é que para que a integração seja boa, eles têm de ser indistinguíveis.

PerCursos: Mas qual o discurso do Estado português, das associações que lidam com os imigrantes?

Francisco Cuberos: Eu acho que é um discurso que historicamente... por suposto do Estado português, isso é seguro. Um Estado nacional onde a única identidade reconhecida como legítima é a identidade nacional, não é. Mas também acho que tem sido interiorizado por muitas outras instituições, não? Há muitas ONGs, muitas... e pessoas... que é esse tipo de pensamento que eu acho que chega a funcionar como sentido comum... acho que pra muita gente, é algo de sentido comum, a boa integração é que não seja reconhecida. 
PerCursos: Não teria a ver também com a questão de uma ex-colônia mais recente? E que ainda tem uma relação hierárquica entre portugueses e cabo-verdianos, uma relação colonial? Resquícios dessa relação colonial? Quer dizer, juntando a questão da etnicidade, da classe? No caso brasileiro deixou de ser colônia há muito tempo. Então está mais distante essa relação colonial.

Francisco Cuberos: Acho que sim. Talvez sim. É possível também que esteja mais presente essa ideia de... Mas no fundo, eu acho que é a mesma coisa. Quer dizer, houve uma hierarquização dentro do Império português que tinha relação sobre tudo: com cor da pele, com o grau de civilização, e claro, lá os africanos ficaram os últimos...

\section{PerCursos: Eu acho que isso pesa muito...}

Francisco Cuberos: Claro, são os últimos também que se "independizaram” numa guerra violenta, também, dependendo, nem em todas as partes foi igual. Lá em Cabo Verde foi muito mais tranquilo. Em Angola foi terrível. Acho que tem a relação também com um discurso que está muito presente em certos setores da sociedade portuguesa, ainda da colonização como civilização, como projeto civilizatório. É muito interessante como encontrei na periferia de Lisboa instituições portuguesas nomeadamente ONGs e grupos religiosos que tinham chegado lá desde a experiência "missioneira", falar de uma gente que saiu fugindo das colônias e que como tinham ficado sem clientela, não? Pra trabalhar. Eram sobretudo irmãs religiosas, coisas assim, e iam para a periferia de Lisboa, onde estavam a chegar os africanos e onde elas achavam que podiam fazer um trabalho de evangelização, como se diz, evangelização/civilização. E ainda tem muito presente esse discurso de, que às vezes não tem uma forma explícita, mas sim, está latente, de que temos de ensinar estas pessoas como é que se funciona, que é a boa forma de viver.

PerCursos: E isso seria o resquício desse passado colonial, bastante presente em Portugal também?

Francisco Cuberos: Eu, pessoalmente, acho que a questão colonial, e isso obviamente a ideia não é minha, todas essas pessoas que têm trabalhado muito a questão colonial, com 
a latinoamérica, Walter Mignolo, Castro Gomes, o Ramón Grosfoguel, no âmbito anglosaxão, temos o Said, toda essa gente, eles têm falado tudo, que realmente o colonialismo fez parte da modernidade e tem entrado na estrutura social e tem um lado mais profundo, e está muito presente na forma de pensar da gente. Às vezes nem siquiera a um nível consciente. É muito interessante como uma pessoa na Espanha pode ter qualquer fonte de formação, mas tem perfeitamente claro qual é a ordem social dentro do mundo, digamos, civilizatório espanhol, né? Não faz falta explicar-lhe que está por cima do índio, e além pra cima de um negro, e isso tem estado muito... Apesar de que a história colonial no caso espanhol aparentemente ficou longe no tempo, não? Mas ainda está muito presente...

PerCursos: Dessa sua experiência de estudos etnográficos em Sevilha e em Lisboa, olhando os processos migratórios, como você pensa esses migrantes nos cenários urbanos que eles passam a integrar? Como é que se dá a relação dos latinoamericanos em Sevilha, com a sociedade de recepção, e dos cabo-verdianos em Lisboa, com a sociedade em torno? É possível pensar comparativamente essas duas experiências?

Francisco Cuberos: No caso espanhol, no caso dos latinoamericanos, é interessante. Eles chegam no começo dos anos 2000, e há um sociólogo que se chama Izquierdo, ele fala dos latinoamericanos que ele chamava de os preferidos. Porque realmente houve um momento... agora no começo do ano 2000, dessa década, em que o Estado espanhol vai preferir e vai tentar que cheguem latinoamericanos. Porque objetivamente há uma demanda de mão de obra mas, pra além disso, há um discurso que constrói o latinoamericano como um imigrante compatível por contraste, nomeadamente como o subsariano, e o magrebe. Isso não é só uma questão de discursos isolados na mídia nem nada disso. É que na própria legislação espanhola os latinoamericanos têm vantagem. Conseguiam entrar sem precisar um visto, podiam ficar até três meses, eram os únicos, porque tinham acordos bilaterais que permitiam isso. Mas também ainda hoje só precisam de dois anos de residência legal na Espanha pra obter a nacionalidade. O resto dos estrangeiros precisam dez. 
PerCursos: Nesse caso, os latinoamericanos são construídos como migrantes mais próximos que os grupos que já estavam estabelecidos na Espanha?

Francisco Cuberos: É muito interessante porque de trás disso há uma construção sobre a proximidade cultural que é totalmente arbitrária porque, por exemplo, constroem o latinoamericano como mais cercano a mi (próximo a mim), que moro a $100 \mathrm{~km}$ de Marrocos. Mas o mesmo Marrocos é visto como se tivesse no meio de um muro e intransponível. Ainda que tenhamos muita cercania na comida, nos espaços públicos, na arquitetura, nas relações familiares, mas há sobretudo uma construção do latinoamericano como cercano (próximo). Nós fizemos um artigo que foi publicado há três anos em que fazíamos uma crítica muito forte desse discurso da proximidade e demonstramos que, na prática, só tinha sido utilizado pra uma substituição de mão de obrano mercado de trabalho espanhol, para "abaratar". No momento em que determinados espaços laborais como a agricultura, o serviço doméstico, a população magrebe, sobretudo, já tinham conseguido se organizar e ter algumas melhorias, que era uma imigração que já tinha quinze anos e... se quer que entre latinoamericanos, de uma forma de baixar o preço. Se você observa, depois disso, como se foi fazendo a imposição da necessidade do visto, que tenho falado que eles não precisavam de visto, mas a partir do ano 2003 o Estado espanhol vai ir impondo a cada país latinoamericano a obrigatoriedade do visto, vai romper os acordos, mas não vai fazer com todos ao mesmo tempo; vai fazer a cada ano, a cada dois anos. Que faz? Quando provê um coletivo, por exemplo os equatorianos, que já estavam mais organizados, porque já tinham três, quatro anos entrando, permite que cheguem muitos bolivianos, e põe visto boliviano, e entra paraguaio. E há uma permanente substituição e uma "baixada" permanente dos salários, e uma precarização permanente. Nesse sentido, a experiência dos latinoamericanos tem sido ambivalente. De um lado tem desfrutado, entre aspas o verbo desfrutar, não? De um discurso que o constrói como preferido, como mais cercano, mas na realidade nunca esse discurso teve uma tradução em melhores condições de integração. Há uma hipocrisia. As condições de integração têm sido tão difíceis como qualquer outro coletivo. A sua participação, em resumo, acho que é muito precária. A 
todos os níveis. E a relação com a sociedade espanhola é sempre precária. Têm os piores postos de trabalho, piores salários, tudo.

PerCursos: Os latinos são parecidos com os espanhóis, mas nem tanto conforme seu relato. No caso dos cabo-verdianos, como ocorrem esses processos de inserção na sociedade portuguesa?

Francisco Cuberos: E no caso dos cabo-verdianos em Lisboa, aí é diferente, porque eles têm já quarenta anos lá. "Tamos” a falar de uma população a qual a maior parte já é de origem cabo-verdiana, mas são nascidos em Portugal e têm a nacionalidade, ou não, às vezes nascem em Portugal, mas não têm a nacionalidade. Mas já é uma realidade muito mais assentada, com várias gerações, que eu acho, com muitos problemas de integração, desde meu ponto de vista, não tem conseguido chegar aos níveis de vida da população e isso é percebido pela população. E é sentido como discriminação, tanto é que estamos a falar de um outro problema mas, não vou dizer mais grave, talvez parecido, mas mais consolidado no tempo.

PerCursos: Esses imigrantes cabo-verdianos encontram-se em que geração no que se refere ao processo migratório, eles estariam já na terceira geração?

Francisco Cuberos: Acho que a quarta já. Si, já a terceira, quarta... E numa variedade de circunstâncias: desde gente que ainda é cabo-verdiana, até gente que são filhos de caboverdianos e que mesmo pelas mudanças legais depois da indepêndencia não vão ter acesso a nacionalidade portuguesa, apesar de terem nascido lá, e... então há muitas situações...

\section{PerCursos: São nascidos em Portugal mas continuam cabo-verdianos?}

Francisco Cuberos: A Lei de Nacionalidade de 1959 privilegiava o princípio de ius soli. Mas em 1981 Portugal aprova uma nova Lei de Nacionalidade que vai dar prioridade ao princípio de ius sanguinis. Esta nova lei vai dificultar o acesso à nacionalidade não só dos 
imigrantes nascidos nas antigas colônias, mas também de seus descendentes, inclusive se eles tiverem nascido já em território atualmente português.

PerCursos: Mas menos acesso à cidadania, ou melhor dizendo, acesso precário à cidadania.

Francisco Cuberos: Si, também que há... Há também muitos latinoamericanos com problemas de cidadania na Espanha. Por que na Espanha? Na Espanha o acesso à cidadania às vezes depende da residência, e a residência depende do trabalho. Então, só quando você consegue a cidadania já pode ficar tranquilo. Até então, a renovação do permisso de residência precisa ter trabalho. Você pode estar legalmente na Espanha e ficar ilegal de pronto se perder o emprego. É o que se chama irregularidad sobrevenida, seja lá na Espanha isso.

PerCursos: Poder nos explicar? Como isso ocorre? Caso esteja na Espanha e perca o emprego....

Francisco Cuberos: E se não consegue um mínimo de meses de trabalho dentro de um ano, não consegue renovar o permisso de residência. O permisso da residência tem uma duração. Quando finaliza você tem de renovar. E pra renovar tem “precisado” cotizar, pagar a segurança social por trabalhar durante um mínimo de meses.

PerCursos: Então, se naquele momento você tiver desempregado já não...

Francisco Cuberos: Se não tem conseguido um mínimo de meses durante esse ano, durante esse período, se não consegue tudo isso, não pode fazer a renovação e fica em condição irregular. Esse problema pra muitos latinoamericanos já não existe, porque pra eles foi relativamente fácil conseguir a cidadania. E lá já termina o problema. 
PerCursos: A lei espanhola para concessão de cidadania é jus soli ou jus sanguinis?

Francisco Cuberos: Jus sanguinis. Então, o fato feito de nascer na Espanha não confere

direito à cidadania espanhola. Acontece que muitos dos nascidos na Espanha já são de padres (pais) que têm cidadania.

PerCursos: Então, no caso, os latinoamericanos...

Francisco Cuberos: No caso dos latinoamericanos... Na Espanha, a única forma de obter a nacionalidade é por ser descendente de espanhol (até duas gerações) ou através do casamento... Si, mas o ser filho também nos casos em que uma pessoa fica em risco de não ter nacionalidade nenhuma. Pode haver. Não sempre, mas pode haver, por exemplo, pessoas que já chegam da África, estão como refugiadas, e não conseguem saber de que cidadania... porque não dizem ou porque o país de origem não reconhece a ele como cidadão. Pode haver alguma... Mas é coisa ocasional, não é uma regra. A regra é que tem que ser por la via do sangue.

PerCursos: Então, nós temos aqui um mestrado em planejamento territorial, desenvolvimento socioambiental, que tem profissionais de diferentes campos de atuação, como empresas ou órgãos públicos, espaços políticos e organizações da sociedade civil. E em sua experiência, como tem se dado a articulação entre participação social e pesquisa acadêmica? Você vem de uma atuação também em ONGs, uma atuação política importante. Nós gostaríamos que falasse como é que como é que você faz o distanciamento necessário para poder produzir conhecimento? O processo de estranhamento daquilo que você está observando em campo, discutindo, participando. Porque nós temos, por exemplo, pessoas que trabalham aqui dentro da Secretaria de Estado e têm que analisar, discutir as questões que acontecem na Secretaria... Nós queríamos ouvi-lo falar um pouco sobre issoporque você vem também de uma experiência de um meio de militância. Queria pensar um pouco sobre isso.

Francisco Cuberos: No caso, eu vou responder a dois níveis: um nível pessoal, de minha experiência pessoal, e depois o que eu acho sobre essa questão. No nível pessoal, para mim nunca tem sido tão difícil porque infelizmente quando trabalhas com migrações, em Sevilha ou em Lisboa, geralmente vais te inserir em mundos que você geralmente não 
habita, siquiera. Tua militância, ainda que seja de esquerda, muito comprometida, geralmente não vá, não tem chegado a essas pessoas. De um lado, no caso de Sevilha, porque é muito recente a chegada dessas pessoas. É interessante como ainda não há uma participação muito forte destas minorias imigrantes em movimentos de esquerda. Só agora é interessante que comecei a ver alguma coisa nos movimentos de luta pela moradia. A Plafatorma de Afectados por la Hipoteca (PAH) que chama; lá se começa a ver porque estão diretamente afetados e... Mas pra mim pessoalmente, eu tinha tido militância a diferentes níveis: nível político, sindical... mas não tinha tido muita relação com este setor da população. Quando chegam, descubro umas culturas, uma forma de vida totalmente diferente. Que você precisa é a tarefa de qualquer antropólogo, entrar nos "seus esquemas", não? E... em geral eu acho que todo esse debate sobre se a militância pode ser uma dificuldade para obter a objetividade necessária, eu sempre acho que esse é um debate que tem um trampa (engano, armadilha). A trampa é que parece que se não tem militância então você é objetivo. Que se você não tem uma implicação ativa numa determinada perspectiva política, porque ninguém percebe, ninguém diz que a pessoa que não faz nada pelos demais, não se implica, também está a tomar uma ação política; também está militando de alguma forma num modelo de vida que não é neutro, nem natural, não é? Um modelo neoliberal; se você não quer entrar em nenhum tipo de debate político e só persegue, por exemplo, a máxima produtividade científica, o teu êxito pessoal, sem criticar nada, pois você está a ter também uma ação política, não? E é muito discutível que isso tem um acesso melhor a objetividade. Ainda mais já em termos de minha experiência prática concreta, a própria militância. Geralmente o que eu tenho encontrado nela é uma cumplicidade muitas vezes pra chegar a informantes e a pessoas... porque afinal é um âmbito da vida a mais. Então, por exemplo, entre os imigrantes latinoamericanos, obviamente há muita gente que tem tido uma experiência associativa, militante, é mais fácil de chegar. Muito mais no meu caso que trabalho o associativismo, onde geralmente as pessoas mais envolvidas vão estar em umas disposições ideológicas mais ou menos cercanas (próximas) as minhas. 
PerCursos: Bem, a outra coisa que queríamos ouvir é sobre essa experiência aqui como antropólogo, estando aqui no Brasil, o que mais chamou a sua atenção, por essa passagem aqui em Florianópolis? A sua experiência, você ficou aqui dois meses, então, você andou por vários lugares, viu muitas coisas e...

Francisco Cuberos: Ah... de um lado, na cidade, me chamou muito a atenção o modelo de cidade é totalmente diferente, realmente, as distâncias. A um nível prático é um modelo diferente, né? Tudo aqui é mais amplo como cidade, mais distante. Com a gente, a relação realmente foi muito boa, me senti muito bem tratado pelos colegas da Udesc. Não tive nenhum problema, tudo bem. Me chamou a atenção uma coisa que vou tentar explicar: eu tenho estado já em diferentes países de Latinoamérica. E... a primeira vez em que estive foi em 2005, 2006, acho, em Equador. Naquele momento me impactou muito a pobreza e a desigualdade. E isso reforçou a ideia preconcebida que ali se tem de que Latinoamérica é um lugar mais pobre que Europa e com mais problemas. Agora, em Florianópolis, não encontrei uma grande diferença com a situação de lá. E eu acho que isso fala de uns níveis de consumo, de vida a cá, mas também de uma tendência lá, é? Acho que, de certa forma, é um... O que cada vez me chama mais atenção é que lá generalizaram-se problemas que até faz pouco não eram comuns e que a gente associava a outros territórios como Latinoamérica. Discussão residencial, de pessoas morando na rua, de serviços básicos muito maus, serviços públicos muito deteriorados. É interessante como há muitos níveis, por exemplo, por dizer que encontrei a cá uma situação melhor do que em Sevilha. Há diferentes níveis. Não tudo. Não tudo. Mas não vi diferenças muito fortes. Enquanto, no ano de 2006, se via diferença muito grande entre Equador e Sevilha. Então isso me devolveu uma imagem diferente da relação Latinoamérica-Europa, que obviamente tem que ver com as diferenças existentes entre os dois pontos de comparação (Equador e Brasil) mas também com a generalização em Europa de problemas sociais que até há pouco não eram tão comuns lá. Acho que isso está muito relacionado também com a minha própria experiência, não é? Também há um ponto de subjetividade lá. Mas, qualquer caso, acho que há essa aproximação em termos de precarização general, de todas as partes, cá, lá, tudo. E depois, o que, uma coisa a nível acadêmico, que encontrei cá e que gostei muito, vi muita colaboração. Porque não só comigo, mas entre a gente. Tem a sensação de que neste Centro, a FAED/UDESC, há 
muito trabalho conjunto, e isso eu gosto. A minha experiência em Sevilha e em Lisboa tem sido boa; eu acompanhei, tenho trabalhado com eles, mas só ao nível de centro... A minha percepção é que não há tanto essa... esse fazer do labor aqui e de eu trabalhar com a gente. Isso eu gostei. E já o nível pessoal encontrei também uma implicação política dos pesquisadores que, pessoalmente, gosto também disso e é compartido com o que hacemos (fazemos) lá, algumas pessoas. Que lá somos minoria e suspeito que cá também. Mas isso é o que encontrei, então essa é intenção, não? Encontra sempre diferença mas também proximidades. Eu acho que... acho que pra qualquer pessoa da Península Ibérica, que vai a Latinoamérica, ou ao revés, latinoamericano que vai lá, acho que sempre temos essa sensação, não, de distância e cercania ao mesmo tempo. Essa é uma coisa...

PerCursos: Teria mais alguma coisa dessa sua experiência que você gostaria de falar? Enfim, sobre a cidade ou sobre futuros trabalhos?

Francisco Cuberos: Outra coisa que gosto de sempre de, na minha experiência, de descobrir. Pra mim novo, sempre que venho para algum ponto de Latinoamérica é sempre você encontrar a realidade local ou regional, não, que sempre fala de coisa que você não sabe. Porque lá o conhecimento é muito pequeno do Brasil, não é? Então, por exemplo, eu sabia que há uma diferença entre o Norte e o Sul do Brasil. Mas quando chega a cá e vê que isso tá muito presente na vida cotidiana, que são os discursos que a gente vê muito presente, que são como quase países diferentes, não é, sociedades muito diferentes. E... e também o próprio enfrentamento com os tópicos que todos temos, não é.... Pra mim há um nível, assim, de percepção visual, né. Pra mim, mais um sítio onde encontrei muita gente ruiva. Muita gente ruiva. Isso está muito afastado do conceito que temos lá do Brasil. Você chega a cá e parece que está mais na Alemanha que... É sempre um tópico. E sempre bate numa situação...

PerCursos: Verdade. E nos bairros de classe média fica mais evidente...

Francisco Cuberos: Si, aonde eu moro não há tantas pessoas assim ruiva... 
PerCursos: Há muita gente do interior que vem para estudar na UFSC e mora por ali. Pessoas que vêm de... que aí realmente elas vem de colônias mesmo... Que ai é outra imagem de Brasil, né?

Francisco Cuberos: Uhum. Claro. E há coisas que não conheço. Ainda que tinha ouvido falar alguma coisa mas não sabia até que ponto está presente. Por exemplo, todo o peso da imigração italiana aqui ou da imigração alemã, não? A imensa, a maior parte da população espanhola você pergunta e, na maioria dos casos vai dizer que os brasileiros estiveram misturados com os portugueses, mas não vão relacionar com italianos ou com os alemães. E é interessante como está muito vivo isso aqui, pelos trabalhos que vi que, as posições dos trabalhos, dos povos que fazem festa. Ainda há uma, toda essa... Si, uma reconstrução dessas identidades...

PerCursos: Ainda há um discurso, tem um discurso valorizando essa identidade. Esses discursos constroem pertencimentos, que marcam e que ajudam a construir essa diferença Sul-Norte no país.

Francisco Cuberos: Que tem também um sentido interno, né? De hierarquização.

PerCursos: Tem um sentido de hierarquização que passa pela noção de raça, civilização. Tem um discurso étnico em torno dessa questão.

Francisco Cuberos: Porque são mais cercanos à civilização. O que também é muito interessante é a falta de sensação de perigo. Porque infelizmente na Europa tem-se criado durante os últimos anos uma ideia de Latinoamérica, e não só de Latinoamérica, em geral de tudo que não é Europa e Estados Unidos, como lugares perigosos. É muito preocupante como, cada vez mais, a ideia de pobreza vinculada ao perigo. E... também acho que é interessante dizer que na minha experiência, nunca vi perigo, é tudo muito tranquilo, não? Acho que pode ter perigo como em qualquer outra cidade, né? Mas, si, em qualquer parte, não? Mas isso também é um contraste, porque eu acho que qualquer pessoa espanhola que vem a cá, num primeiro momento vai vir pra ver isso, pra ver como 
é... Infelizmente a ideia que se tem do Brasil é... especialmente se é na cidade, na favela, tudo isso.

PerCursos: É, em outras metrópoles talvez seja bem mais perigoso, mas Florianópolis ainda é relativamente tranquila. Uma capital de porte médio, mas interessantes as suas observações. Agradecemos por suas reflexões e esperamos continuar esse diálogo.

Francisco Cuberos: Foi um prazer!

Recebida em: 10/06/2015 Aprovada em: 16/06/2015

Universidade do Estado de Santa Catarina - UDESC

Centro de Ciências Humanas e da Educação - FAED

Revista PerCursos

Volume 16 - Número 30 - Ano 2015 revistapercursos@gmail.com 